\title{
Standardization of recipe for the preparation of drink from rhododendron (Rhododendron arboreum Sm.) flower extract
}

\section{N.S. Thakur, Aarti, Abhimanyu Thakur ${ }^{\star}$, Hamid and Sunakshi Gautam}

Department of Food Science and Technology, Dr. Yashwant Singh Parmar University of Horticulture and Forestry, Nauni, Solan-173230, Himachal Pradesh, India

\begin{tabular}{|c|c|}
\hline Article Info & Abstract \\
\hline $\begin{array}{l}\text { Article history } \\
\text { Received } 3 \text { April } 2021 \\
\text { Revised } 10 \text { May } 2021 \\
\text { Accepted } 11 \text { May } 2021 \\
\text { Published Online } 30 \text { June } 2021\end{array}$ & $\begin{array}{l}\text { Rhododendron (Rhododendron arboreum Sm.) belonging to family Ericaceae is an evergreen shrub or } \\
\text { small tree which bears bright red edible flowers. The flowers exhibit many medicinal properties and are } \\
\text { rich source of carbohydrates, amino acids, sugars, pectin, anthocyanins and vitamin C. So, investigations } \\
\text { were conducted to exploit its wide quality parameters for the development of drink on commercial scale } \\
\text { for its proper utilization. Eight combinations of flower extract and TSS for the preparation of rhododendron } \\
\text { drink were tried. With the increase in extract content of different recipes, there was a significant effect }\end{array}$ \\
\hline $\begin{array}{l}\text { Keywords } \\
\text { Rhododendron } \\
\text { Beverage } \\
\text { Drink } \\
\text { Flower extract } \\
\text { RTS }\end{array}$ & $\begin{array}{l}\text { on physicochemical characteristics of rhododendron drink. The recipe with } 14 \text { per cent extract, } 12^{\circ} \mathrm{B} \text { TSS } \\
\text { and } 0.30 \text { per cent acidity was found best on the basis of its sensory parameters and some physicochemical } \\
\text { characteristics. The mean values for various sensory characteristics like colour, body, taste, aroma and } \\
\text { overall acceptability of the standardized recipe of drink were observed as } 8.37,8.08,8.50,7.24 \text { and } 8.40 \text {, } \\
\text { respectively. }\end{array}$ \\
\hline
\end{tabular}

\section{Introduction}

Rhododendron (Rhododendron arboreum Sm.) is one of the wild plants of Himachal Pradesh which is commonly known as "burans" and known for its highly valued wild edible flowers (Kashyap et al., 2017). The term rhododendron has been derived from two Greek words "rhodo" and "dendron" which means rose and tree, respectively. The various species of rhododendron are concentrated in the temperate regions of Northern hemisphere especially in SinoHimalayas including China, Japan, Myanmar, Thailand, Malaysia, Indonesia, Philippines, New Guinea, Afghanistan, Pakistan, India, Nepal, southern Europe and northern America (Heywood et al., 2007; Singh et al., 2009). In Himachal Pradesh, three species, namely; Rhododendron arboreum Sm., Rhododendron campanulatum $\mathrm{D}$. and Rhododendron anthopogen $\mathrm{D}$. are distributed in the forests of Bilaspur, Sirmour, Chamba, Kangra, Kullu, Shimla, Kinnaur and Solan districts (Pradhan and Lachungpa, 1990; Chauhan, 1999). Out of all species available, the most important and stately known is Rhododendron arboreum $\mathrm{Sm}$. with deep scarlet to red, pink and white flowers (Thakur et al., 2020a). The deep red to scarlet red flowers of Rhododendron arboreum Sm. are sweetish sour in taste which have been found to be rich source of carbohydrates, amino acids, sugars, pectin, anthocyanins and vitamin C (Solanki et al., 2013; Kashyap et al., 2017). Its flowers possess pharmacological and biological properties and traditionally

\footnotetext{
Corresponding author: Dr. Abhimanyu Thakur Assistant Professor, Department of Food Science and Technology, Dr. Yashwant Singh Parmar University of Horticulture and Forestry, Nauni, Solan-173230, Himachal Pradesh, India

E-mail: abhimanyuthakurprashar@gmail.com Tel.: +91-9882239719
}

Copyright $(\odot 2021$ Ukaaz Publications. All rights reserved. Email: ukaaz@yahoo.com; Website: www.ukaazpublications.com the flowers are used for curing diarrhea, blood dysentery, high altitude sickness, headache, mental retardation, nasal bleeding, fever and stomach ache (Popesco and Kopp, 2013; Thakur et al., 2020b). Its flowers being rich source of vitamin $\mathrm{C}$ have been found to have high antioxidant and free radical scavenging activities (Shrestha and Budhathoki, 2012). The unique antioxidant activity and various antioxidant compounds contribute towards its medicinal value, human health benefits and helps in the prevention of various neurodegenerative disorders (Kalaycioglu and Erim, 2017; Thakur et al., 2019). So, being a rich source of antioxidants specially colour pigments like anthocyanins as well as sugars, this fruit can be exploited for the development of some beverages specially drink. Thus, the present studies were undertaken to standardize the recipe for preparation of drink from rhododendron (Rhododendron arboreum $\mathrm{Sm}$.) flower extract.

\section{Materials and Methods}

\subsection{Raw material and extraction of extract}

The flowers of Rhododendron arboreum Sm. procured from Rajgarh area of Sirmour district of Himachal Pradesh in the month of April were brought to the Department of Food Science and Technology, UHF, Nauni, Solan (HP), where they were used to carry out the research work. The flower identification and authentication was carried out by Department of Forest Products, Dr. YSPUHF, Nauni, Solan, India vide-UHF herbarium number-13915, YSPUHF, Solan, India. The flowers were further used for the preparation of flower extract by using flower petals and cooked in 15 per cent hot water for $6 \mathrm{~min}$ followed by 0.08 per cent pectinase treatment for $60 \mathrm{~min}$ at $50^{\circ} \mathrm{C}$. This flower extract was further used for the development of rhododendron drink. 


\subsection{Development of rhododendron drink}

Flower drink was prepared by mixing different proportions of rhododendron flower extract in different combinations of sugar syrup as given in Table 1. The flow sheet for the preparation of rhododendron drink has been given in Figure 1. To get the desirable concentration of acid $(0.30 \%)$ in flower drink, citric acid was added in different treatment combinations. Sodium benzoate (120 ppm) was added in all the treatments as a preservative.

Table 1: Treatment detail of rhododendron flower drink

\begin{tabular}{|l|c|c|c|c|c|c|c|c|}
\hline Treatment & $\mathrm{T}_{1}$ & $\mathrm{~T}_{2}$ & $\mathrm{~T}_{3}$ & $\mathrm{~T}_{4}$ & $\mathrm{~T}_{5}$ & $\mathrm{~T}_{6}$ & $\mathrm{~T}_{7}$ & $\mathrm{~T}_{8}$ \\
\hline Flower extract (\%) & 10 & 12 & 14 & 16 & 10 & 12 & 14 & 16 \\
\hline TSS $\left({ }^{\circ} \mathrm{B}\right)$ & 12 & 12 & 12 & 12 & 15 & 15 & 15 & 15 \\
\hline
\end{tabular}

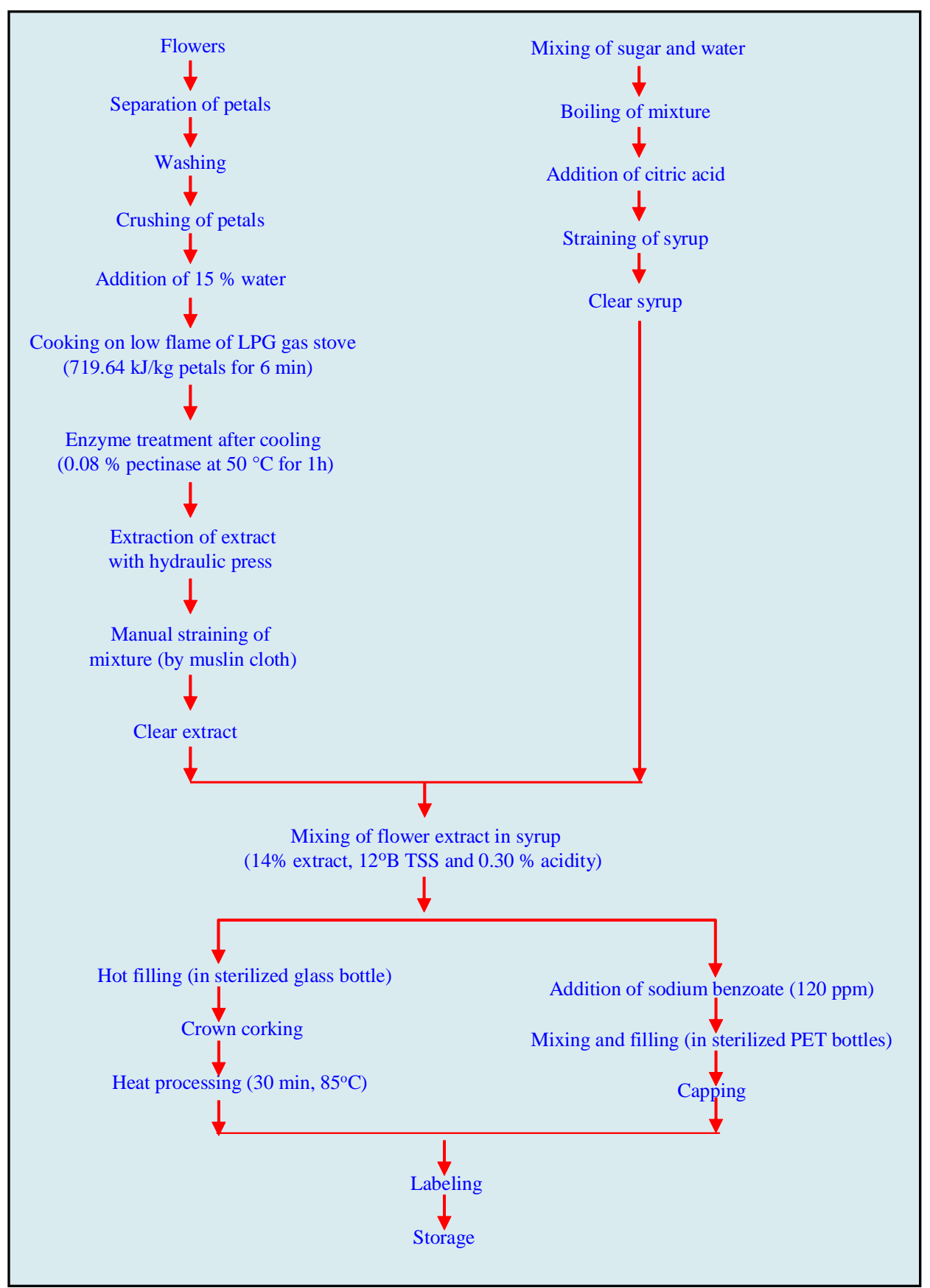

Figure 1: Unit operations for the preparation of rhododendron drink. 


\subsection{Physicochemical analysis}

\subsubsection{Colour}

The colour of drink in terms of different units (red and yellow) was observed with a Tintometer (Lovibond Tintometer Model E).

\subsubsection{Apparent viscosity}

The apparent viscosity of the flower extract and various beverages was determined by using Ostwald viscometer and was expressed in terms of time (flow rate in minutes) taken for samples to pass through the tube.

\subsubsection{Total soluble solids (TSS)}

TSS of drink measured by hand refractrometers ranging from 0 to 32 and expressed as ${ }^{\circ} \mathrm{Brix}\left({ }^{\circ} \mathrm{B}\right)$.

\subsubsection{Titratable acidity}

Titratable acidity was estimated by titrating a known volume of sample against standard $\mathrm{NaOH}$ using phenolphthalein as an indicator. The titratable acidity was expressed as per cent citric acid (Ranganna, 2009) as per given formula:

Titratable acidity $\%$ (as citric acid $)=$

Titre value $\times$ Normality of alkali $\times$

Volume made $\times$ Equivalent weight of dominating acid Weight of sample taken for estimation

$\times$ Volume of aliquot $\times 1000$

\subsection{5 pH}

The $\mathrm{pH}$ of drink was determined by using a digital $\mathrm{pH}$ meter (CRISON Instrument, Ltd. Spain). Before estimating the $\mathrm{pH}$ of sample, $\mathrm{pH}$ meter was standardized with standard buffers of 4,7 and 9 .

\subsubsection{Sugars}

Sugars were estimated by Lane and Eynon method given by Ranganna (2009). A known volume of sample was neutralized with $\mathrm{NaOH}$ and to it $2 \mathrm{ml}$ of lead acetate was added and kept as such for ten min. Excess of lead acetate was removed by adding $2 \mathrm{ml}$ of potassium oxalate in $250 \mathrm{ml}$ volumetric flask. After diluting it up to the mark, the solution was filtered and clear filtrate was taken to estimate reducing sugars by titrating against a known quantity of Fehling's A and Fehling's B solutions using methylene blue as an indicator. Reducing sugars were estimated as per cent and calculated as given below:

$$
\begin{aligned}
& \text { Reducing sugars } \%=\frac{* \text { Factor } \times \text { Dilution }}{\text { Titre value } \times \text { Weight } / \text { Volume of sample }} \times 100 \\
& * \text { Factor }=0.05
\end{aligned}
$$

Total sugars were estimated by adding $5 \mathrm{~g}$ of citric acid to $50 \mathrm{ml}$ of calibrated sample (prepared for reducing sugars) and heated for 10 min. For complete inversion of sugar samples, $\mathrm{NaOH}$ was added and final volume $250 \mathrm{ml}$ was made. The total sugars were estimated as per cent and calculated as:

Total sugars $\%=\frac{* \text { Factor } \times \text { Dilution }}{\text { Titre value } \times \text { Weight } / \text { Volume of sample }} \times 100$

$$
* \text { Factor }=0.05
$$

\subsubsection{Ascorbic acid}

Ascorbic acid content was determined by using 2-6 dichlorophenol indophenol visual titration method (Ranganna, 2009). Samples were prepared with 3 per cent meta-phosphoric acid and aliquot was titrated with dye to pink colour end point. The results were expressed as $\mathrm{mg} / 100 \mathrm{ml}$ of sample and calculated as per formula:

$$
\begin{array}{r}
\underset{\text { Ascorbic acid }}{(\mathrm{mg} / 100 \mathrm{ml})}=\frac{\text { Titre value } \times \text { * Dye factor }}{\times \text { Volume made }} \\
\text { Aliquot taken } \times \text { Weight } / \text { Volume of sample } \\
* \text { Dye factor }=0.5 / \text { Titre value }
\end{array}
$$

Titre value for dye factor was determined by titrating standard Lascorbic acid prepared in 3 per cent metaphosphoric acid with 2-6 dichlorophenol indophenol dye to a pink colour end point.

\subsubsection{Anthocyanins}

Total anthocyanins present in all samples were determined by spectrophotometric method given by Ranganna (2009). The procedure involves extraction of anthocyanins with 85 per cent ethanolic $\mathrm{HCl}$ and measuring its optical density at $535 \mathrm{~nm}$. Anthocyanins were calculated and expressed as mg/100 ml using the formula given below:

$$
\begin{aligned}
& \text { Total OD mg/ } 100 \mathrm{ml}(\mathrm{x})= \\
& \text { OD of sample } \times \text { Volume made up of extracts } \\
& \times \text { Total volume at } 535 \mathrm{~nm} \text { for colour measurement } \\
& \text { Volume of extract used } \times \text { Volume / weight of sample taken } \\
& \text { Total anthocyanins }(\mathrm{mg} / 100 \mathrm{ml})=\frac{\mathrm{X}}{* 98.20} \\
& \text { * } 98.20=\text { Extraction coefficient }
\end{aligned}
$$

\subsubsection{Total phenols}

Total phenols content was determined by Folin-Ciocalteu procedure given by Singleton and Rossi (1965) in which absorbance was measured at $765 \mathrm{~nm}$ in a colourimeter against water blank. One gram of sample was taken and ground with $10 \mathrm{ml}$ of 80 per cent ethanol in pestle and mortar and centrifuged for $20 \mathrm{~min}$ at 10000 $\mathrm{rpm}$ and filtered. Filtrate was evaporated in oven up to the dryness and dried extract was dissolved in $5 \mathrm{ml}$ distilled water. $2 \mathrm{ml}$ aliquot was taken in separate test tube and volume was made upto $3 \mathrm{ml}$. Then, $0.5 \mathrm{ml}$ Folin-Ciocalteu reagent was added. Phenols with phosphomolybdic acid in Folin-Ciocalteu reagent and in alkaline medium produce a highly dark blue coloured complex (molybdenum blue). After $3 \mathrm{~min}, 2 \mathrm{ml}$ of $\mathrm{Na}_{2} \mathrm{CO}_{3}(20 \%)$ was added and mixed. Test tubes were placed in boiling water bath for one minute and then cooled. The concentration was determined as per the standard procedure from the standard curve. A standard calibration curve of gallic acid using its different concentrations was prepared and concentration of total phenols in the given sample was calculated as $\mathrm{mg} \mathrm{GAE} / 100 \mathrm{ml}$ of sample.

\subsubsection{Antioxidant activity}

Antioxidant activity (free radical scavenging activity) was measured as per the method of Brand-Williams et al. (1995). DPPH (2, 2- 
diphenyl-1-picrylhydrazyl) was used as a source of free radical. A quantity of $3.9 \mathrm{ml}$ of $6 \times 10^{-5} \mathrm{~mol} / 1 \mathrm{DPPH}$ in methanol was put into a cuvette with $0.1 \mathrm{ml}$ of sample extract and the decrease in absorbance was measured at $515 \mathrm{~nm}$ for $30 \mathrm{~min}$ or until the absorbance become steady. Methanol was used as a blank. The remaining DPPH concentration was calculated using the following equation:

$$
\text { Antioxidant activity }(\%)=\frac{\begin{array}{c}
\text { Absorbance of blank }(\mathrm{DPPH})- \\
\text { Absorbance of sample }
\end{array}}{\text { Absorbance of blank }(\mathrm{DPPH})} \times 100
$$

\subsection{Sensory evaluation}

The sensory evaluation of different recipes of flower drink was carried out by hedonic rating test (Amerine et al., 1965). The samples were evaluated for different sensory characteristics like colour, body, taste, aroma and overall acceptability. Semi-trained sensory panel (10 numbers at a time) comprised of faculty members and postgraduate students of Department of Food Science and
Technology, UHF, Solan (HP) were selected randomly. This random selection was made so as to accommodate different sections and age groups to evaluate the various sensory parameters (Thakur et al., 2018a).

\subsection{Statistical analysis}

Data on physicochemical characteristics of flower drink was analyzed by completely randomized design (CRD) whereas, data pertaining to the sensory evaluation were analyzed by using randomized block design (RBD). The experiment for recipe standardization was replicated three times.

\section{Results}

\subsection{Standardization of recipe for the development of rhododendron drink}

The data pertaining to physicochemical and sensory characteristics of rhododendron drink prepared by different recipes has been presented in Tables 2 and 3.

\begin{tabular}{|c|c|c|c|c|c|c|c|c|c|c|c|c|}
\hline \multirow[b]{2}{*}{ Treatments } & \multicolumn{2}{|c|}{ Colour } & \multirow{2}{*}{$\begin{array}{l}\text { Apparent } \\
\text { viscosity } \\
\text { (Min) }\end{array}$} & \multirow[b]{2}{*}{$\begin{array}{l}\text { TSS } \\
\left({ }^{\circ} \mathbf{B}\right)\end{array}$} & \multirow{2}{*}{$\begin{array}{c}\text { Titratable } \\
\text { acidity } \\
(\%)\end{array}$} & \multirow[b]{2}{*}{$\mathbf{p H}$} & \multicolumn{2}{|c|}{ Sugars $(\%)$} & \multirow{2}{*}{$\begin{array}{l}\text { Ascorbic } \\
\text { acid } \\
\text { (mg/100 } \\
\text { ml) }\end{array}$} & \multirow{2}{*}{$\begin{array}{c}\text { Anthocyanins } \\
(\mathrm{mg} / \mathbf{1 0 0} \\
\mathrm{ml})\end{array}$} & \multirow{2}{*}{$\begin{array}{c}\text { Total } \\
\text { phenols } \\
(\mathrm{mg} \mathrm{GAE} / \\
100 \mathrm{ml})\end{array}$} & \multirow{2}{*}{$\begin{array}{l}\text { Antioxidant } \\
\text { activity (\%) }\end{array}$} \\
\hline & $\mathbf{R}$ & $\mathbf{Y}$ & & & & & $\begin{array}{c}\text { Total } \\
\text { sugars }\end{array}$ & $\begin{array}{c}\text { Reducing } \\
\text { sugars }\end{array}$ & & & & \\
\hline $\mathbf{T}_{1}$ & 3.65 & 0.85 & 3.19 & 12 & 0.30 & 4.04 & 9.50 & 6.70 & 0.45 & 7.31 & 10.17 & 6.54 \\
\hline $\mathbf{T}_{2}$ & 3.89 & 0.68 & 4.26 & 12 & 0.30 & 4.05 & 9.76 & 6.91 & 0.85 & 8.98 & 12.21 & 8.09 \\
\hline $\mathbf{T}_{3}$ & 3.96 & 0.55 & 5.11 & 12 & 0.30 & 4.09 & 9.98 & 7.05 & 1.43 & 9.86 & 14.24 & 9.66 \\
\hline $\mathbf{T}_{4}$ & 4.01 & 0.41 & 5.27 & 12 & 0.30 & 4.16 & 10.17 & 7.21 & 1.95 & 11.44 & 16.28 & 11.21 \\
\hline $\mathbf{T}_{5}$ & 3.91 & 0.81 & 5.28 & 15 & 0.30 & 4.05 & 12.86 & 8.92 & 0.46 & 7.35 & 10.19 & 6.55 \\
\hline$T_{6}$ & 4.21 & 0.65 & 5.01 & 15 & 0.30 & 4.08 & 12.90 & 8.93 & 0.88 & 9.03 & 12.22 & 8.10 \\
\hline $\mathbf{T}_{7}$ & 4.44 & 0.50 & 5.39 & 15 & 0.30 & 4.12 & 12.95 & 8.95 & 1.44 & 9.97 & 14.25 & 9.67 \\
\hline $\mathbf{T}_{8}$ & 4.59 & 0.37 & 5.51 & 15 & 0.30 & 4.17 & 13.01 & 8.96 & 1.99 & 11.52 & 16.30 & 11.24 \\
\hline $\mathrm{CD}_{0.05}$ & 0.13 & 0.10 & 0.24 & - & - & 0.06 & 0.15 & 0.10 & 0.27 & 0.22 & 0.37 & 0.42 \\
\hline S.E. & 0.11 & 0.06 & 0.28 & - & - & 0.02 & 0.59 & 0.38 & 0.22 & 0.57 & 0.86 & 0.66 \\
\hline
\end{tabular}

Table 2: Physicochemical characteristics of different recipes of rhododendron drink

No. of replications $=3$; S.E. $=$ Standard error

\subsubsection{Physicochemical characteristics}

Data presented in Table 2 indicate that visual red and yellow TCU of drink ranged between 3.65 to 4.59 and 0.37 to 0.85 , respectively among different recipes. The maximum (4.59) red TCU were recorded in $\mathrm{T}_{8}$ and lowest (3.65) in $\mathrm{T}_{1}$. The highest (0.85) yellow TCU were recorded in $\mathrm{T}_{1}$ and lowest $(0.37)$ in $\mathrm{T}_{8}$ which were statistically at par with $\mathrm{T}_{4}$. The apparent viscosity of drink ranged between 3.19 to $5.51 \mathrm{~min}$. The lowest $(3.19 \mathrm{~min}$ ) apparent viscosity was recorded in $\mathrm{T}_{1}$ and highest $(5.51 \mathrm{~min})$ in $\mathrm{T}_{8}$ which was at par with $\mathrm{T}_{4}, \mathrm{~T}_{5}$ and $\mathrm{T}_{7}$.

During preparation of the product, TSS of first four recipes were maintained at $12^{\circ} \mathrm{B}$ and rest at $15^{\circ} \mathrm{B}$, whereas, the titratable acidity of all the recipes was maintained as 0.30 per cent. The $\mathrm{pH}$ of the drink ranged between 4.04 to 4.17 , highest (4.17) in $\mathrm{T}_{8}$ which was at par with $\mathrm{T}_{7}$ and $\mathrm{T}_{4}$ and lowest (4.04) in $\mathrm{T}_{1}$ which was at par with $\mathrm{T}_{2}, \mathrm{~T}_{3}, \mathrm{~T}_{5}$ and $\mathrm{T}_{6}$. The total and reducing sugars content of the drink ranged between 9.50 to 13.01 and 6.70 to 8.96 per cent, respectively. The highest $(13.01 \%)$ total sugars content was recorded in $\mathrm{T}_{8}$ which was statistically at par with $\mathrm{T}_{5}, \mathrm{~T}_{6}$ and $\mathrm{T}_{7}$, and the lowest $(9.50 \%)$ in $\mathrm{T}_{1}$. The maximum $(8.96 \%)$ reducing sugars content was recorded in $\mathrm{T}_{8}$ which was statistically at par with $\mathrm{T}_{5}, \mathrm{~T}_{6}$ and $\mathrm{T}_{7}$ and minimum $(6.70 \%)$ in $\mathrm{T}_{1}$. The ascorbic acid content of drink varied from 0.45 to $1.99 \mathrm{mg} / 100 \mathrm{ml}$ in the product and highest $(1.99 \mathrm{mg} / 100 \mathrm{ml})$ was recorded in $\mathrm{T}_{8}$ which is at par with $\mathrm{T}_{4}$ and lowest ascorbic acid content $(0.45 \mathrm{mg} / 100 \mathrm{ml})$ was observed in $\mathrm{T}_{1}$ which was statistically at par with $\mathrm{T}_{5}$. The anthocyanins content of different recipes of rhododendron drink ranged between 7.31 to $11.52 \mathrm{mg} / 100 \mathrm{ml}$. The highest $(11.52 \mathrm{mg} / 100 \mathrm{ml})$ value of anthocyanins recorded in $\mathrm{T}_{8}$ which was statistically at par with $\mathrm{T}_{4}$ and lowest $(7.31 \mathrm{mg} / 100 \mathrm{ml})$ 
in $T_{1}$ which was statistically at par with $T_{5}$. Total phenols content of different recipes of this beverage ranged between 10.17 to 16.30 mg GAE/100 ml. It was recorded highest $(16.30 \mathrm{mg} / 100 \mathrm{ml})$ in $\mathrm{T}_{8}$ which was statistically at par with $\mathrm{T}_{4}$ and lowest $(10.17 \mathrm{mg} / 100$ $\mathrm{ml}$ ) in $\mathrm{T}_{1}$ which was statistically at par with $\mathrm{T}_{5}$. The antioxidant activity of drink ranged between 6.54 to 11.24 per cent and highest $(11.24 \%)$ was recorded in $\mathrm{T}_{8}$ which was at par with $\mathrm{T}_{4}$ and lowest $(6.54 \%)$ in $\mathrm{T}_{1}$ which was at par with $\mathrm{T}_{5}$.

From the above results, it is found that with the increase in extract content of different recipes a significant effect on physicochemical characteristics of rhododendron drink was observed.

Table 3: Sensory characteristics (scores) of different recipes of rhododendron drink

\begin{tabular}{|c|c|c|c|c|c|}
\hline Treatments & Colour & Body & Taste & Aroma & $\begin{array}{c}\text { Overall } \\
\text { acceptability }\end{array}$ \\
\hline $\mathbf{T}_{\mathbf{1}}$ & 8.00 & 7.73 & 7.17 & 7.07 & 7.06 \\
\hline $\mathbf{T}_{\mathbf{2}}$ & 8.07 & 7.83 & 7.33 & 7.18 & 7.20 \\
\hline $\mathbf{T}_{\mathbf{3}}$ & 8.37 & 8.08 & 8.50 & 7.24 & 8.40 \\
\hline $\mathbf{T}_{\boldsymbol{4}}$ & 8.27 & 7.97 & 7.73 & 7.22 & 8.00 \\
\hline $\mathbf{T}_{\mathbf{5}}$ & 8.01 & 7.83 & 7.87 & 7.02 & 7.17 \\
\hline $\mathbf{T}_{\mathbf{6}}$ & 8.11 & 7.93 & 8.03 & 7.13 & 7.60 \\
\hline $\mathbf{T}_{\mathbf{7}}$ & 8.28 & 8.05 & 7.20 & 7.21 & 7.23 \\
\hline $\mathbf{T}_{\mathbf{8}}$ & 8.31 & 8.07 & 7.00 & 7.22 & 7.07 \\
\hline $\mathbf{C D}_{\mathbf{0 . 0 5}}$ & 0.03 & 0.02 & 0.24 & 0.01 & 0.18 \\
\hline $\mathbf{S . E}_{\mathbf{0}}$ & 0.05 & 0.05 & 0.18 & 0.03 & 0.17 \\
\hline
\end{tabular}

No. of replications $=3$; S.E. $=$ Standard error

Table 4: Physicochemical and sensory characteristics of standardized recipe of rhododendron drink

\begin{tabular}{|c|c|c|}
\hline \multicolumn{2}{|c|}{ Characteristics } & Mean values $\pm \mathrm{SE}$ \\
\hline \multicolumn{3}{|c|}{ Physicochemical } \\
\hline \multirow[t]{2}{*}{ Colour (TCU) } & Red & $3.96 \pm 0.07$ \\
\hline & Yellow & $0.55 \pm 0.07$ \\
\hline \multicolumn{2}{|c|}{$\begin{array}{l}\text { Apparent viscosity } \\
\text { (Flow rate in min) }\end{array}$} & $5.11 \pm 0.12$ \\
\hline \multicolumn{2}{|l|}{ TSS $\left({ }^{\circ} B\right)$} & 12.00 \\
\hline \multicolumn{2}{|c|}{ Reducing sugars $(\%)$} & $7.05 \pm 0.07$ \\
\hline \multicolumn{2}{|c|}{ Total sugars $(\%)$} & $9.98 \pm 0.07$ \\
\hline \multicolumn{2}{|c|}{ Titratable acidity $(\%)$} & 0.30 \\
\hline \multicolumn{2}{|l|}{$\overline{\mathrm{pH}}$} & $4.09 \pm 0.02$ \\
\hline \multicolumn{2}{|c|}{ Ascorbic acid $(\mathrm{mg} / 100 \mathrm{ml})$} & $1.43 \pm 0.10$ \\
\hline \multicolumn{2}{|c|}{ Anthocyanins $(\mathrm{mg} / 100 \mathrm{ml})$} & $9.86 \pm 0.10$ \\
\hline \multicolumn{2}{|c|}{ Total phenols $(\mathrm{mg}$ GAE/100 ml) } & $14.24 \pm 0.12$ \\
\hline \multicolumn{2}{|c|}{ Antioxidant activity (\%) } & $9.66 \pm 0.40$ \\
\hline \multicolumn{3}{|c|}{ Sensory (Scores) } \\
\hline \multicolumn{2}{|l|}{ Colour } & $8.37 \pm 0.08$ \\
\hline \multicolumn{2}{|l|}{ Body } & $8.08 \pm 0.33$ \\
\hline \multicolumn{2}{|l|}{ Taste } & $8.50 \pm 0.50$ \\
\hline \multicolumn{2}{|l|}{ Aroma } & $7.24 \pm 0.33$ \\
\hline \multicolumn{2}{|c|}{ Overall acceptability } & $8.40 \pm 0.40$ \\
\hline
\end{tabular}

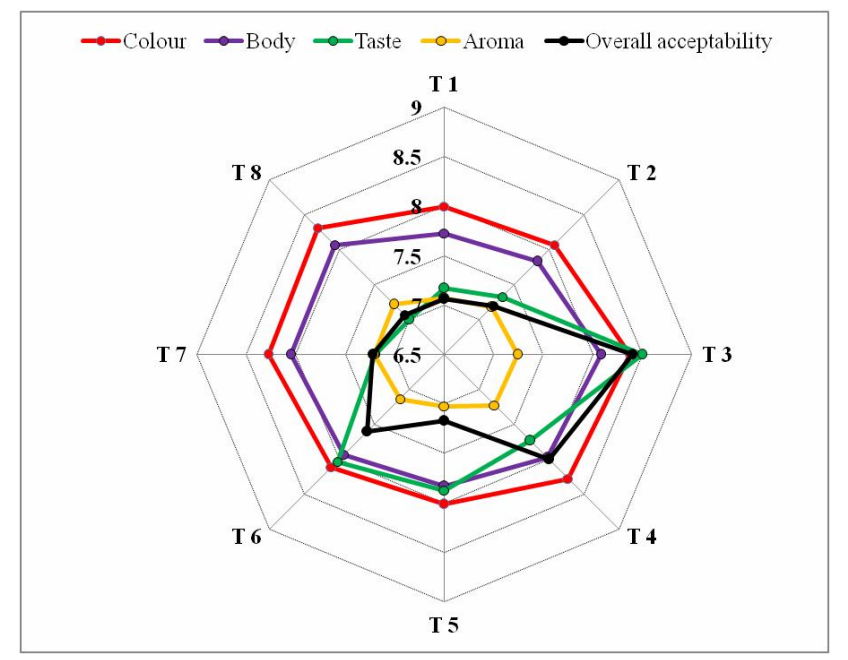

Figure 2: Sensory characteristics (scores) of different recipes of rhododendron drink.

\subsubsection{Sensory characteristics}

Data on sensory characteristics of different recipes of rhododendron drink given in Table 3 and Figure 2 indicate that the highest (8.37) colour score was obtained in recipe $\mathrm{T}_{3}$ and lowest (8.00) in $\mathrm{T}_{1}$. The recipe $\mathrm{T}_{3}$ obtained maximum body score as 8.08 and minimum (7.73) in $T_{1}$. The highest score (8.50) of taste was also awarded to $\mathrm{T}_{3}$ while $\mathrm{T}_{8}$ got the lowest (7.00) which was statistically at par with $\mathrm{T}_{1}$ and $\mathrm{T}_{7}$. The maximum (7.24) score of aroma was obtained in recipe $T_{3}$ and minimum (7.02) in $T_{5}$. The highest score (8.40) of overall acceptability was awarded to recipe $\mathrm{T}_{3}$ and the lowest (7.06) to $\mathrm{T}_{1}$ which was closely followed by $\mathrm{T}_{2}, \mathrm{~T}_{5}, \mathrm{~T}_{7}$ and $\mathrm{T}_{8}$.

From the above results, it was concluded that the recipe with 14 per cent extract, $12^{\circ} \mathrm{B}$ TSS and 0.30 per cent acidity $\mathrm{T}_{3}$ was found to be best on the basis of sensory and some physicochemical characteristics of the drink.

\subsection{Physicochemical and sensory characteristics of stan-} dardized recipes of rhododendron drink

A perusal of data given in Table 4 shows that red and yellow TCU of standardized recipe of drink were observed as $3.96 \pm 0.07$ and $0.55 \pm 0.07$, respectively. Apparent viscosity, TSS, reducing sugars and total sugars of this product were recorded as $5.11 \pm 0.12 \mathrm{~min}$, $12.00^{\circ} \mathrm{B}, 7.05 \pm 0.07$ and $9.98 \pm 0.07$ per cent, respectively. Titratable acidity and $\mathrm{pH}$ of drink were observed as 0.30 and 4.09 \pm 0.02 , respectively. The product also contained ascorbic acid (1.43 $\pm 0.10 \mathrm{mg} / 100 \mathrm{ml})$, anthocyanins $(9.86 \pm 0.10 \mathrm{mg} / 100 \mathrm{ml})$, total phenols $(14.24 \pm 0.12 \mathrm{mg} \mathrm{GAE} / 100 \mathrm{ml})$ and antioxidant activity $(9.66 \pm 0.40 \%)$. The mean values of sensory characteristics like colour, body, taste, aroma and overall acceptability of standardized recipe of drink were obtained as $8.37 \pm 0.08,8.08 \pm 0.33,8.50 \pm$ $0.50,7.24 \pm 0.33$ and $8.40 \pm 0.40$, respectively.

\section{Discussion}

The recipe $\mathrm{T}_{4}$ and $\mathrm{T}_{8}$ recorded higher values of anthocyanins, total phenols, ascorbic acid, total sugars, reducing sugars, apparent viscosity and antioxidant activity which clearly due to the use of higher amount of flower extract as compared to other recipes. The 
changes in extract content in different recipes had also affected the colour units of the drink. Data given in Table 3 show that there was a significant effect of extract acid-syrup blend on sensory scores of different recipes of rhododendron drink. The higher colour and body scores of recipes $T_{8}$ and $T_{3}$ might be due to better combination of extract-syrup blend as compared to other recipes. The changes in extract content in different recipes have also affected the taste and aroma score of the drink. The recipe $\mathrm{T}_{3}$ obtained the highest taste score which was clearly due to the higher extract content used as well as better sugar-acid-extract blend in this recipe. The higher overall acceptability scores of recipe $\mathrm{T}_{3}$ might also be due to the better combination of extract-acid-syrup blend coupled with attractive colour and body of the product. Similar results have been reported by Thakur et al. (2017) in box myrtle drink, Hamid et al. (2017) in mulberry drink, Thakur et al. (2018b) in wild aonla drink, Sharma et al. (2019) in apple-whey based herbal functional readyto-serve beverage, Chauhan et al. (2019) in wild prickly pear beverage, Bhatt et al. (2020) in wild jamun beverage and Thakur $e t$ $a l$. (2020c) in wild prickly pear fruit drink.

\section{Conclusion}

From the above results, it was observed that this standardized recipe of rhododendron drink (14 per cent extract, $12^{\circ} \mathrm{B}$ TSS and 0.30 per cent acidity) contained relatively higher ascorbic acid, total phenols, anthocyanins and antioxidant activity along with best sugar-acid blend, which was because of higher content of flower extract used in this recipe. This recipe also obtained maximum scores for sensory parameters like colour, body, taste, aroma and overall acceptability, which might be due to higher extract content, best combination of extract and syrup, best sugar-acid blend in the product and finally all these factors might have led the judges to award the highest scores to this recipe.

\section{Conflict of interest}

The authors declare that there are no conflicts of interest relevant to this article.

\section{References}

Amerine, M.A.; Pangborn, R.M. and Roessler, E.B. (1965). Principles of sensory evaluation of food. Academic Press, London, pp:236-268.

Brand-Williams, W.; Cuvelier, M. E. and Berset, C. (1995). Use of free radical method to evaluate antioxidant activity. Lebensmittel-Wissenschaft and Technologie, 28:25-30.

Bhatt, K.; Thakur, N.S.; Thakur, A.; Hamid and Sharma, C. (2020). Standardization of recipe for the preparation of wild jamun squash: Effect of packaging materials and temperature conditions on nutritional quality during storage. International Research Journal of Pure and Applied Chemistry, 21(12):34-44. https://doi.org/ 10.9734/IRJPAC/2020/v21i1230232

Chauhan, M.; Thakur, N.S. and Thakur, A. (2019). Development of spiced squash (appetizer) from wild prickly pear (Opuntia dillenii Haw.) and its quality evaluation during storage. Journal of Applied and Natural Science, 11(2):315-320. https://www.doi.org/10.31018/ jans.v11 i 2.2049

Chauhan, N.S. (1999). Medicinal and aromatic plants of Himachal Pradesh. Indus Publishing Company, New Delhi, pp:351-356.

Hamid.; Thakur, N.S.; Kumar, P. and Thakur, A. (2017). Studies on preparation and preservation of ready-to-serve (RTS) beverage from underutilized mulberry (Morus alba L.) fruits and its quality evaluation during storage. International Journal of Current Microbiology and Applied Sciences, 6(9):1067-1079.

Heywood, N.H.; Brummitt, R.K.; Culham, A. and Seberg, G. (2007). Flowering plant families of the World. The Brown Reference Group, London.

Kalaycioglu, Z. and Erim, F.B. (2017). Total phenolic contents, antioxidant activities and bioactive ingredients of juices from pomegranate cultivars worldwide. Food Chem., 221:496-507. https://www.doi. org/10.1016/j.foodchem.2016.10.084.

Kashyap, P.; Anand, S. and Thakur, A. (2017). Evaluation of antioxidant and antimicrobial activity of Rhododendron arboreum flowers extract. International Journal of Food and Fermentation Technology, 7(1):123-128. https://www.doi.org/10.5958/22779396.2017.00013.7.

Popescu, R. and Kopp, B. (2013). The genus Rhododendron: An ethnopharmacological and toxicological review. Journal of Ethnopharmacology, 147:42-62.

Pradhan, U.C. and Lachungpa, S.T. (1990). Sikkim-Himalayan rhododendron. Primulaceae Books, Darjeeling, pp:450.

Ranganna, S. (2009). Handbook of analysis and quality control for fruit and vegetable products. Tata McGraw Hill Co. Ltd., New Delhi. pp:1112.

Sharma, R.; Choudhary, R.; Thakur, N.S. and Thakur, A. (2019). Development and quality of apple-whey based herbal functional ready-to-serve beverage. Journal of Applied and Natural Science, 11(2):291-298. https://www.doi.org/10.31018/jans.v11i2.2047

Shrestha, R.M. and Budhathoki, N.P.S. (2012). The chemical compositions of Rhododendron arboreum, "Laligunras". Journal of Nepal Chemical Society, 30:97-106. https://doi.org/10.3126/jncs.v30i0. 9376

Singelton, V.L. and Rossi, J.A. (1965). Colorimetry of total phenolics with phosphomolybedic phosphotungstic acid reagent. American Journal of Enology and Viticulture, 16:144-158.

Singh, K.K.; Rai, L.K. and Gurung B. (2009). Conservation of rhododendron in Sikkim Himalaya: An overview. World Journal of Agriculture Sciences, 5:284-296.

Solanki, S.N.; Huria, A.K. and Chopra, C.S. (2013). Physicochemical characterstics of buransh (Rhododendron arboreum Sm.) a nutritious and edible flower. Journal of Hill Agriculture, 4:50-52.

Thakur, A.; Thakur, N.S. and Kumar, P. (2017). Preparation of Myrica nagi (Box myrtle) drink and effect of storage temperature on its quality. Journal of Applied and Natural Science, 9(4):2137-2142. https:// www.doi.org/10.31018/jans.v9i4.1500

Thakur, A.; Joshi, V. K. and Thakur, N. S. (2019). Immunology and its relation with food components: an overview. International Journal of Food and Fermentation Technology, 9(1):1-16. https://www.doi. org/10.30954/2277-9396.01.2019.3.

Thakur, N.S.; Aarti; Gautam, S.; Chandel, A.; Rana, N.; Thakur, A. and Hamid (2020a). Comparative assessment of Rhododendron (Rhododendron arboreum $\mathrm{Sm}$.) flowers extract beverages through biochemical analysis and its quality evaluation during storage. Ann. Phytomed., 9(2):223-231. http://dx.doi.org/10.21276/ap. 2020.9.2.20.

Thakur, N.S.; Aarti; Hamid; Thakur, A. and Gautam, S. (2020b). Utilization of edible rhododendron (Rhododendron arboreum $\mathrm{Sm}$.) flowers for development of spiced beverage (appetizer) and its shelf life evaluation during storage. International Research Journal of Pure and Applied Chemistry, 21:52-62. 
Thakur, N.S.; Chauhan, M. and Thakur, A. (2020c). Studies on development and storage quality evaluation of betalains rich drink prepared from wild prickly pear (Opuntia dillenii Haw.) fruits. The Bioscan., 15(1):9-13.

Thakur, N.S.; Thakur, N.; Thakur, A.; Kumar, P. and Hamid (2018a). Physicochemical characteristics and standardization of juice extraction method from wild aonla (Phyllanthus emblica L.) fruits of Himachal Pradesh, India. International Journal of Current
Microbiology and Applied Sciences, 7(2):731-737. https:// www.doi.org/10.20546/ijcmas.2018.702.092

Thakur, N.S.; Thakur, N.; Hamid; Kumar, P. and Thakur, A. (2018b). Formulation and optimization of vitamin $\mathrm{C}$ rich ready-to-serve juice based beverage from wild aonla fruits and its quality evaluation during storage. Journal of Pharmacognosy and Phytochemistry, 7(1):1796-1802.

N.S. Thakur, Aarti, Abhimanyu Thakur, Hamid and Sunakshi Gautam (2021). Standardization of recipe for the preparation of drink from rhododendron (Rhododendron arboreum Sm.) flower extract. J. Phytonanotech. Pharmaceut. Sci., 1(2):10-16. http://dx.doi.org/10.21276/jpps.2021.1.2.2 